\title{
Why is care in the community perceived as a failure?
}

\author{
JULIAN LEFF
}

Ask any gathering of people who are not members of the psychiatric profession what they think of care in the community and most, if not all of them, will reply that it has failed. The phrase 'in the community' has even entered common parlance to indicate that a person is 'off his head' or 'barmy' (Leff, 2000). The media almost universally hold to this conviction, and judging from their intention to introduce a more restrictive Mental Health Act, the Government of England and Wales is of the same mind. How has this come about when there is substantial evidence of considerable success resulting from the revolution in psychiatric care that has occurred over the past 50 years? Few lay people are aware that of the 130 psychiatric hospitals functioning in England and Wales in 1975 , only 14 remain open, with fewer than 200 patients in each. The fact that this is not better publicised is an indication of the Government's reservations about the outcome of the policy of deinstitutionalisation endorsed by their predecessors, both of the left and of the right.

\section{THE INVISIBILITY OF A COMMUNITY SERVICE}

A number of sources of this general misperception can be identified. Perhaps the most potent is the term 'care in the community' itself. What image of success could it conjure up? The community as a concept is nebulous and often evokes scepticism regarding its existence. A good community psychiatric service is virtually invisible. The residences for patients needing sheltered accommodation are intentionally indistinguishable from neighbouring homes, in accordance with the philosophy of normalisation. The network of professionals needs to be based in a building in the catchment area, but this often is a converted house with nothing identifiable about its exterior.
Community psychiatric staff do not wear distinctive uniforms: even those who are medically qualified do not carry black bags and stethoscopes. Psychiatric admission wards often are an integral part of the general hospital and not evident to the casual passer-by. Thus the dramatic architectural presence of the asylums has been replaced by an apparent absence.

\section{HOMELESSNESS}

What is conspicuous to the public is the increase in homeless people on the streets, many of whom obviously are mentally ill. This is linked in the minds of the public and of some professionals with the closure of the asylums. The number of homeless people in England doubled during the decade of the 1980s but has since remained at about 400000 according to Shelter (2001). The earlier rise was partly a result of a reduction in the availability of low-cost accommodation and partly due to the closure of direct-access hostels, which "since the mid-1950s have served as unacknowledged asylums for large numbers of mentally ill people" (Craig \& Timms, 1992). The proportion of homeless people with severe mental illness has remained steady at between a quarter and a half (Craig \& Timms, 1992; Fisher et al, 1994; Hamid et al, 1995; Adams et al, 1996). Thus, the public were correct in perceiving an increase in the absolute number of conspicuously mentally ill people on the streets during the 1980 s, but where have they come from?

A number of surveys have shown that very few homeless men with mental illness have spent any length of time in a psychiatric hospital (Timms \& Fry, 1989; Craig \& Timms, 1992; Hamid et al, 1995). The situation may be different for homeless women with mental illness (Marshall \& Reed, 1992; Adams et al, 1996) and homeless people in Belfast
(McCauley \& MacKenna, 1995). Selection biases may account for these conflicting findings but are avoided by prospective follow-up studies of long-stay patients resettled in the community. Pickard et al (1991) followed up 103 such patients discharged from Cane Hill Hospital and found that none became homeless in the first year. A similar picture emerged from a follow-up of 150 patients discharged from Tooting Bec Hospital (Craig \& Timms, 1992), whereas the Team for the Assessment of Psychiatric Services (TAPS) study of a cohort of 670 long-stay patients found that a maximum of four became homeless over 5 years following discharge (Leff \& Trieman, 2000). The problem of homeless people with mental illness is a blight on community care but is not a consequence of the failure of planned resettlement of patients from psychiatric hospitals.

\section{VIOLENCE}

The other overriding issue for the public and the media is that of violence by people with mental illness. In fact, the staff in the closing psychiatric hospitals strove to prevent patients with a history of violence, or a propensity to it, from being discharged into the community, and such patients formed a large part of the difficult-to-place group who were cared for in highly staffed and specialised facilities (Trieman \& Leff, 1996). Furthermore, careful analysis of the figures for violent crime has revealed that people with mental illness are not especially prone to violent acts and that, if anything, there has been a decrease in violent crimes committed by people with mental illness in recent years (Taylor \& Gunn, 1999). Part of the misperception of the situation is a confusion in the mind of the public between schizophrenia and personality disorder, engendered by the false equivalence of schizophrenia with split personality. A single homicide by a person with mental illness or personality disorder, emblazoned by the media, is sufficient to reinforce the public association of violence with mental ill health and the assumption that 'care in the community' is responsible.

\section{COMPLEXITY}

Another influential factor is the dispersed nature of a modern psychiatric service. 
The psychiatric hospital was an extreme exemplar of centralisation. A comprehensive community psychiatric service is a complex network of interlinked facilities and professionals encompassing multiple disciplines and agencies. The latter often include National Health Service (NHS) trusts, local authorities, social services, voluntary organisations and private facilities, making up a 'mixed economy of care'. Even wellinformed journalists find it difficult to grasp the entirety of a community service and the fact that some needs of patients may be well served but others unmet. It is hardly surprising, then, that members of the public generally make an all-or-nothing judgement concerning success or failure.

Psychiatric professionals are well aware of the problems within their own ambit of responsibility, and where a service is in dire trouble, as are many admission wards, it becomes common knowledge within the profession. However few members of the public are aware of this particular problem unless they have a relative with psychiatric illness who has needed admission. It is curious that journalists view waiting lists for medical and surgical emergencies as hot news, whereas the same problem affecting psychiatric patients does not seem to merit exposure. The disadvantage of a low or invisible profile in the media is that governments feel little pressure to find a solution.

It is probably fair to state that a comprehensive community psychiatric service catering to all the needs of the catchment area population exists nowhere in the British Isles and will never be achieved. This is because health service provision is always chasing need in an ascending spiral. When basic needs are satisfied, a new level of need becomes apparent. This is another reason why the judgement of the success of a service cannot be absolute and must be relative.

\section{REMEDIES}

What can be done to alter the perception of the public, the media and the Government that care in the community has failed? Although the conspicuous presence of mentally ill homeless people is not a direct consequence of closure of the psychiatric hospitals, it represents a mass of human misery for which our profession must take responsibility. People admitted to a psychiatric ward from a hostel for the homeless

JULIAN LEFF, FRCPsych, Social Psychiatry Section, Institute of Psychiatry, De Crespigny Park, Denmark Hill, London SE5 8AF, UK

(First received I6 January 200I, final revision 19 April 200I, accepted 23 April 200I)

are "discharged prematurely back to the hostel, often with no warning and without follow-up arrangements" (Marshall \& Reed, 1992). My own experience of caring for admitted patients, $20 \%$ of whom were homeless or from out of the catchment area, taught me that a period of rehabilitation extending over a year or more could re-establish many of them in a settled way of life. Unfortunately, this is seen as an unattainable luxury under the conditions of today's admission wards. Longterm rehabilitation units are an essential component in any community service.

In recent years a number of campaigns have been launched with the aim of combatting the stigma of mental illness. These include the Mind campaign entitled 'Respect', the ongoing World Psychiatric Association Campaign Against the Stigma of Schizophrenia Worldwide and the Royal College of Psychiatrists' campaign 'Changing Minds: Every Family in the Land'. Each of these aims to raise public awareness of the essential humanity of people with psychiatric problems and the need to integrate them into society instead of excluding them on account of their 'otherness'. However, none of these campaigns focuses on educating the public and the media about the reality of community care.

Not all of our colleagues are convinced that closing the psychiatric hospitals was the right policy to pursue. When the proposed closure of Claybury Hospital was announced in 1983, the consultants resisted and refused to allow their patients to be assessed for possible discharge. This 'strike' lasted for 6 months and then collapsed, and Claybury closed in 1997. Active resistance by psychiatrists has ceased but there is a general passivity about community care when what is needed is advocacy and positive action. Many patients in the community lead impoverished and aimless lives, exacerbated by the lack of gainful employment and the difficulty of making friends outside of the circle of providers and users of psychiatric services. These problems can be solved: Pathfinder NHS Trust has implemented a policy of employing people with psychiatric illness, who now constitute $10 \%$ of the Trust's workforce. An experimental campaign to educate neighbours about the problems and needs of psychiatric patients moving into a sheltered home in their street was successful in promoting social interaction and friendships with the new residents (Wolff et al, 1996).

A new generation of psychiatrists is growing up who not only have never worked in a psychiatric hospital but have never seen one! All of us need to accept the role of 'product champions' for community care and, by our actions, to promote the social and occupational integration of patients, become more visible in our local communities now that the protection of the asylum walls is no more. Few, if any, of us would wish to return to the era of the asylums and, if we do not undertake a public relations job of this kind, we and our clients are likely to face increasingly restrictive mental health legislation enacted by governments pandering to public misperceptions.

\section{DECLARATION OF INTEREST}

Funding for the Team for the Assessment of Psychiatric Services was received from the Department of Health and North East Thames Regional Health Authority.

\section{REFERENCES}

Adams, C. E., Pantelis, C., Duke, P. J., et al (1996) Psychopathology, social and cognitive functioning in a hostel for homeless women. British Journal of Psychiatry, 168, 82-86.

Craig, T. K. J. \& Timms, P.W. (1992) Out of the wards and onto the streets? Deinstitutionalization and homelessness in Britain. Journal of Mental Health, I, 265-275.

Fisher, N., Turner, S. W., Pugh, R., et al (1994) Estimating numbers of homeless and homeless mentally ill people in north east Westminster by using capture-recapture analysis. British Medical Journal, 308, 27-30.

Hamid, W. A., Wykes, T. \& Stansfeld, S. (1995) The social disablement of men in hostels for homeless people. II. A comparison with patients from long-stay wards. British Journal of Psychiatry, 166, 809-812.

Leff, A. (2000) Clean round the bend - the etymology of jargon and slang terms for madness. History of Psychiatry, II, I55-162. 
Leff, J. \& Trieman, N. (2000) Long-stay patients discharged from psychiatric hospitals. Social and clinical outcomes after five years in the community. The TAPS Project 46. British Journal of Psychiatry, I76, 217-223.

Marshall, E. J. \& Reed, J. L. (1992) Psychiatric morbidity in homeless women. British Journal of Psychiatry, 160, 76I-768.

McCauley, A. \& MacKenna, H. P. (1995) Mental disorder among a homeless population in Belfast: an exploratory study. Journal of Psychiatric and Mental Health Nursing, 2, 335-342.
Pickard, L., Proudfoot, R. \& Wolfson, P. (1991) The Closure of Cane Hill Hospital: Report of the Cane Hill Evaluation Team. London: Research \& Development for Psychiatry.

Shelter (200I) Housing and Homelessness in England: The Facts. Policy Unit, Shelter: London.

Taylor, P. J. \& Gunn, J. (1999) Homicides by people with mental illness: myth and reality. British Journal of Psychiatry, 174, 9-14.
Timms, P.W. \& Fry, A. H. (1989) Homelessness and mental illness. Health Trends, 2I, 70-7I.

Trieman, N. \& Leff, J. (1996) Difficult to place patients in a psychiatric hospital closure programme. The TAPS Project 24. Psychological Medicine, 26, 765-774.

Wolff, G., Pathare, S., Craig, T., et al (1996) Public education for community care. A new approach. British Journal of Psychiatry, 168, 44I-447. 